\title{
The effect of ischaemia on the excitability of sensory nerves in diabetes mellitus
}

\author{
K. N. SENEVIRATNE AND O. A. PEIRIS \\ From the Departments of Physiology and Medicine, Faculty of Medicine, University of Ceylon, \\ Colombo
}

A reduction of the conduction velocity in the motor nerves of diabetic patients has been shown by Mulder, Lambert, Bastron, and Sprague (1961), Skillman, Johnson, Hamwi, and Driskill (1961), and Lawrence and Locke (1961). They found evidence of slowing of the conduction velocity in patients who had evidence of a clinical neuropathy, and by statistical comparison demonstrated a reduced conduction velocity in some of their diabetic subjects who had no clinical evidence of a neuropathy. Downie and Newell (1961) and Gilliatt and Willison (1962), using evoked potential techniques, have demonstrated an absence or a diminution of the sensory nerve action potential with a slowing of the distal conduction velocity in diabetics. A reduction of the conduction velocity was however not a constant feature in all diabetics, for Lawrence and Locke (1961) and Skillman et al. (1961) have observed conduction velocities as fast or faster than the mean values for controls in several of their diabetic subjects who had clinical evidence of a peripheral neuropathy.

Poole (1956a) has shown that ischaemic and postischaemic paraesthesiae occur very constantly in healthy subjects between the ages of 12 to 60 years, when the circulation in the upper limb is restored after it has been occluded for a certain minimum duration. Poole (1956b) also showed that these paraesthesiae were absent or diminished in intensity or duration in subjects who had evidence of peripheral sensory nerve disease.

In this study, excitability changes in relation to ischaemia in the sensory nerves of patients with diabetes mellitus have been investigated. We have in the accompanying paper (Seneviratne and Peiris, 1968) shown that there is a good correlation between these excitability changes and the times of onset and duration of ischaemic and post-ischaemic paraesthesiae.

\section{METHODS}

Twelve male subjects between the ages of 15 and 45 , suffering from diabetes mellitus, were selected for this study. Diabetes mellitus was diagnosed according to the $\frac{\bar{\sigma}}{\bar{\nabla}}$ criteria recommended by WHO (1965).

A careful clinical examination was carried out on allo subjects in order to assess peripheral nerve function. All ${ }_{-}^{\text {S }}$ such examinations were done by one of us. A system of $\vec{O}$ scoring was designed so that each positive symptom or $\vec{\overrightarrow{ }}$ sign from a list was allotted one point, the maximum $\omega_{\sigma}$ possible score being 15 points. The following symptoms? and signs were considered: pain in the legs, paraesthesiae in arms or legs, loss of sensation in the arms or legs, $\dot{\omega}$ muscular weakness, sensory loss to pin-prick in the legs.only, sensory loss to pin-prick in both legs and arms, losss of light touch, loss of vibration sense (a) at the ank (b) at the iliac crest, (c) at the wrist; calf tenderness, 100 of ankle jerks, loss of other deep reflexes, muscle weaknerss on testing, and, lastly, wasting of muscles.

Conventional electro-diagnostic tests of nerve function $>$ were done on all patients. A score of one point wosso allotted to each abnormality detected, so that maximư severity as judged by these means indicated three point The measurements made for this purpose were the motor 6 conduction in one external popliteal nerve, the latency of 9 the sensory action potential at the wrist obtained by the method described (Seneviratne and Peiris, 1968), and the amplitude of this potential. The lowest values in normal subjects for these parameters were $35.6 \mathrm{~m} / \mathrm{sec}$ (Thomas, Sears, and Gilliatt, 1959), $2.7 \mathrm{msec}$, and $66 \mu \mathrm{V}$ respec- $\frac{\mathrm{Q}}{\mathrm{Q}}$ tively (Seneviratne and Peiris, 1968).

When divided in this manner, the subjects studied $\overrightarrow{\vec{F}}$ could be assigned to two groups, Group A comprising 3 patients who had no clinical or conventional electrical $\supset$ abnormality in their peripheral nerves and Group B patients who had either clinical or conventional electrical abnormalities or both. There were six subjects of comparable age in each group.

Vascular occlusion was obtained by using an ordinaryo sphygmomanometer cuff placed on the upper arm. In? all cases the resting systolic blood pressure was measured and occlusion applied by rapidly inflating the cuff to a3 pressure $80 \mathrm{~mm}$ above the resting systolic pressure. This pressure was higher than used in normal subjects to compensate for a possible increase in rigidity of the vessels of diabetic subjects. The response to a submaximal stimulus was recorded during and after a half- $N$ hour period of vascular occlusion by the method described ${ }^{\circ}$ in the accompanying paper (Seneviratne and Peiris, $\mathcal{O}$ 1968). Latency measurements were made from the be- 
ginning of the stimulus artefact to the peak of the positive pre-potential. Response amplitude was measured from the peak of the negative to the peak of the positive spike, while response duration was measured from the peak of the positive pre-potential to the peak of the main downgoing deflection.

\section{RESULTS}

Table I gives the details of the clinical and electrical scores of the 12 subjects.

Figure 1 shows the distribution of potential size and latency in the 12 diabetic subjects and in a control group of $\mathbf{4 0}$ subjects, in response to a supra-maximal stimulus. These results are summarized in Table II.

Figures 2 and 3 illustrate the effects of ischaemia on one diabetic subject of Group A. The test stimulus used was one which evoked a response $45 \%$ of maximum. During the first few minutes of ischaemia there is a small increase in the size of the response, after which the effect of asphyxia become evident. The response diminishes in size till at the 30th minute it is $72 \%$ of its pre-ischaemic size. During the first 2 min of the post-ischaemic period, the response increases in size to $85 \%$, remains at or near this size for $15 \mathrm{~min}$, and then continues to recover its size more slowly over the next $13 \mathrm{~min}$.

The most constant and characteristic feature of these 12 experiments was the persistence of a relatively large response up to the 30 th minute of ischaemia. In these subjects the mean response size at the end of the ischaemic period was $62 \%$ (range

\section{TABLE I}

CLINICAL AND ELECTRICAL FINDINGS IN 12 DIABETIC SUBJECTS

\begin{tabular}{lll} 
Age $(y r)$ & $\begin{array}{l}\text { Clinical } \\
\text { score }\end{array}$ & $\begin{array}{l}\text { Electrical } \\
\text { score }\end{array}$ \\
\hline
\end{tabular}

\begin{tabular}{ccccc}
\hline $\begin{array}{l}\text { Group A } \\
\text { Subjects 1-6 }\end{array}$ & $42,24,18$ & 0 & 0 \\
& $40,15,40$ & & \\
Group B & & & \\
Subject & 1 & 23 & 11 & 1 \\
& 2 & 45 & 6 & 3 \\
& 3 & 36 & 9 & 3 \\
& 4 & 32 & 7 & 3 \\
& 5 & 23 & 2 & 1 \\
6 & 45 & 1 & 1
\end{tabular}

TABLE II

MAXIMUM EVOKED RESPONSE SIZE AND LATENCY IN DIABETICS AND CONTROLS

\begin{tabular}{|c|c|c|c|c|c|c|}
\hline & \multicolumn{3}{|c|}{ Response size $(\mu V)$} & \multicolumn{3}{|c|}{ Latency (msec) } \\
\hline & Mean & S.D. & Range & Mean & S.D. & Range \\
\hline $\begin{array}{l}\text { Controls (40) } \\
\text { Group A (6) } \\
\text { Group B (6) }\end{array}$ & $\begin{array}{r}103 \\
97 \\
45\end{array}$ & $\begin{array}{l}26 \cdot 2 \\
22 \cdot 7 \\
13 \cdot 8\end{array}$ & $\begin{array}{l}66-170 \\
70-132 \\
20-58\end{array}$ & $\begin{array}{l}2 \cdot 0 \\
2 \cdot 1 \\
2 \cdot 5\end{array}$ & $\begin{array}{l}0 \cdot 2 \\
0 \cdot 2 \\
0 \cdot 6\end{array}$ & $\begin{array}{l}1 \cdot 7-2 \cdot 7 \\
1 \cdot 9-2 \cdot 5 \\
1 \cdot 9-3 \cdot 5\end{array}$ \\
\hline
\end{tabular}

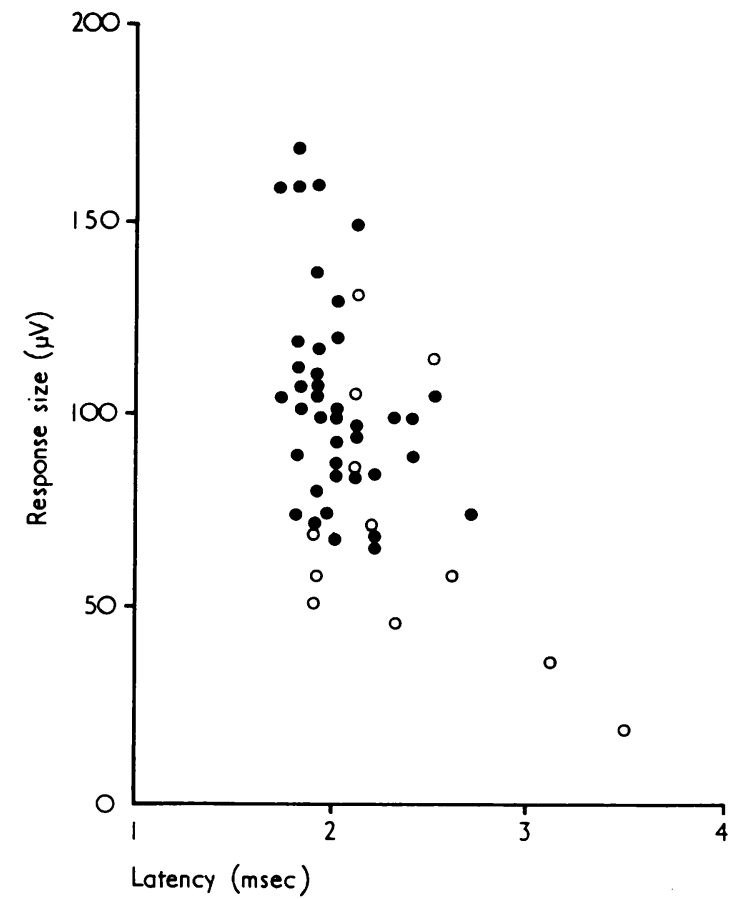

FIG. 1. Latency and size of response evoked by a supramaximal stimulus in 40 normal subjects (O) and 12 diabetics $(\mathrm{O})$.

$46-72 \%$ ). At the end of the second minute after release of the cuff the response had increased in size to a mean value of $75 \%$ (range $46-90 \%$ ), indicating a recovery of only $13 \%$ (range $0-18 \%$ ) during this period.

Three of the 12 subjects showed an increase in response size up to $120 \%$ during early ischaemia, while only one showed a post-ischaemic rise of up to $120 \%$. None of the subjects reported the occurrence of ischaemic or post-ischaemic paraesthesiae. Results from nine subjects are shown graphically in Figure 4.

In the 12 subjects a $30-$ min period of ischaemia increased the latency of the response from a mean value of $2.3 \mathrm{msec}$ (range 1.9-3.5 msec) to a mean value of $2.9 \mathrm{msec}$ (range $2.5-4.0 \mathrm{msec}$ ). During this period, the duration of the response increased from a mean value of $1.1 \mathrm{msec}$ (range $0.8-1.3 \mathrm{msec}$ ) to $1.3 \mathrm{msec}$ (range 0.9-1.6 $\mathrm{msec}$ ).

Figure 5 compares the size, duration, and latency of the responses at the 26 th minute of ischaemia in the 12 diabetic subjects with those obtained from 12 subjects of the control group. It is evident that ischaemia alters these characteristics of the evoked response in the diabetic subjects by a significantly smaller amount than in controls. 
FIG. 2. Effects of ischaemia on the compound action potential evoked by a sub-maximal stimulus. Upper row: during ischaemia; lower row: after release of the cuff. Figures indicate time in minutes.

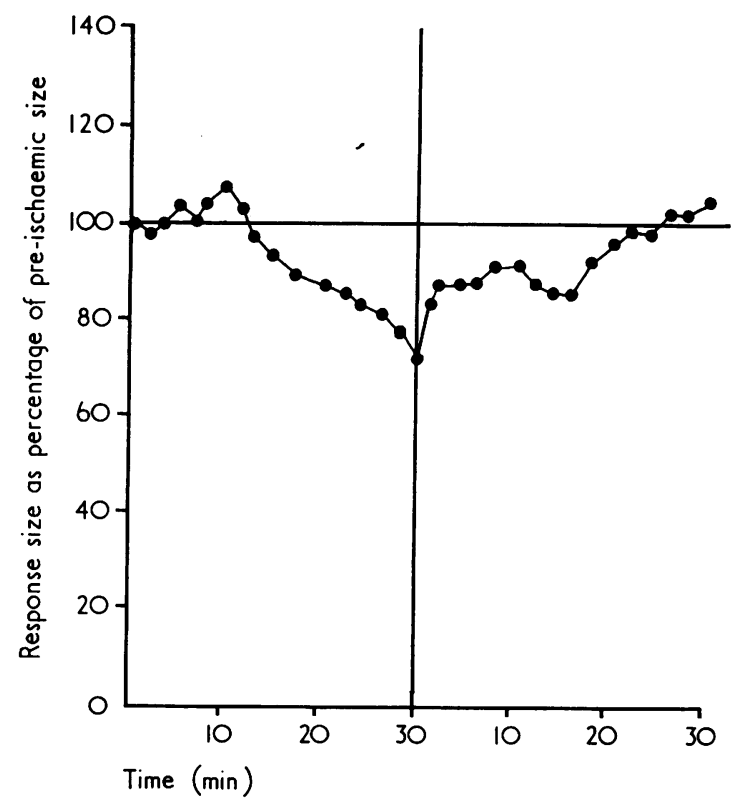

FIG. 3. Results of Fig. 2 represented graphically.

Figure 6 (a) shows the effect of ischaemia on the response size in microvolts in six diabetic subjects; three of these subjects were from Group $A$ and three from Group B. Figure 6 (b) contrasts these changes with those that occurred in five subjects from the control group.
DISCUSSION

The results expressed in Figs. 6(a) and 6(b) i dicate that the response of the nerves of diabetie $?$ subjects to ischaemia is very different from that of normal subjects. Further, the results illustrated $\stackrel{0}{9}$ Fig. 6(a) show that this difference is common to $\overrightarrow{0}$ the diabetic subjects of Group A who had no clinicat ${ }_{\infty}$ or electrical evidence of a neuropathy, as well as to those of Group B who had definite evidence of a peripheral nerve disorder.

Figure 5 shows that the diminution of the response amplitude and the increase of response latency and duration are far less marked in the diabetic subject than in the normal control. These features indicate $\overline{0}$ that the sensory nerves of diabetic subjects are more resistant to the effects of asphyxia than those of normal subjects.

It may be argued that this difference in behaviour is due to the fact that pathological changes occurring in the diabetic nerve selectively inactivate those fibres which are susceptible to the effects of asphyxia, leaving intact only those that are more resistant. The evidence presented here does not support this view. It has been shown (Seneviratne and Peiris, 을 1968) that in normal subjects the contribution to the $D$ potential made by the high threshold fibres whose activity persists after $\mathbf{3 0} \mathrm{min}$ of ischaemia is not more $\overline{\mathrm{N}}$ than $20 \%$ of the maximum evoked potential. In the $\sigma$ six subjects of Group A, however, the maximum $\mathbb{O}$ evoked response ranges from 70-132 $\mu \mathrm{V}$ and the $\underset{\omega}{N}$ 

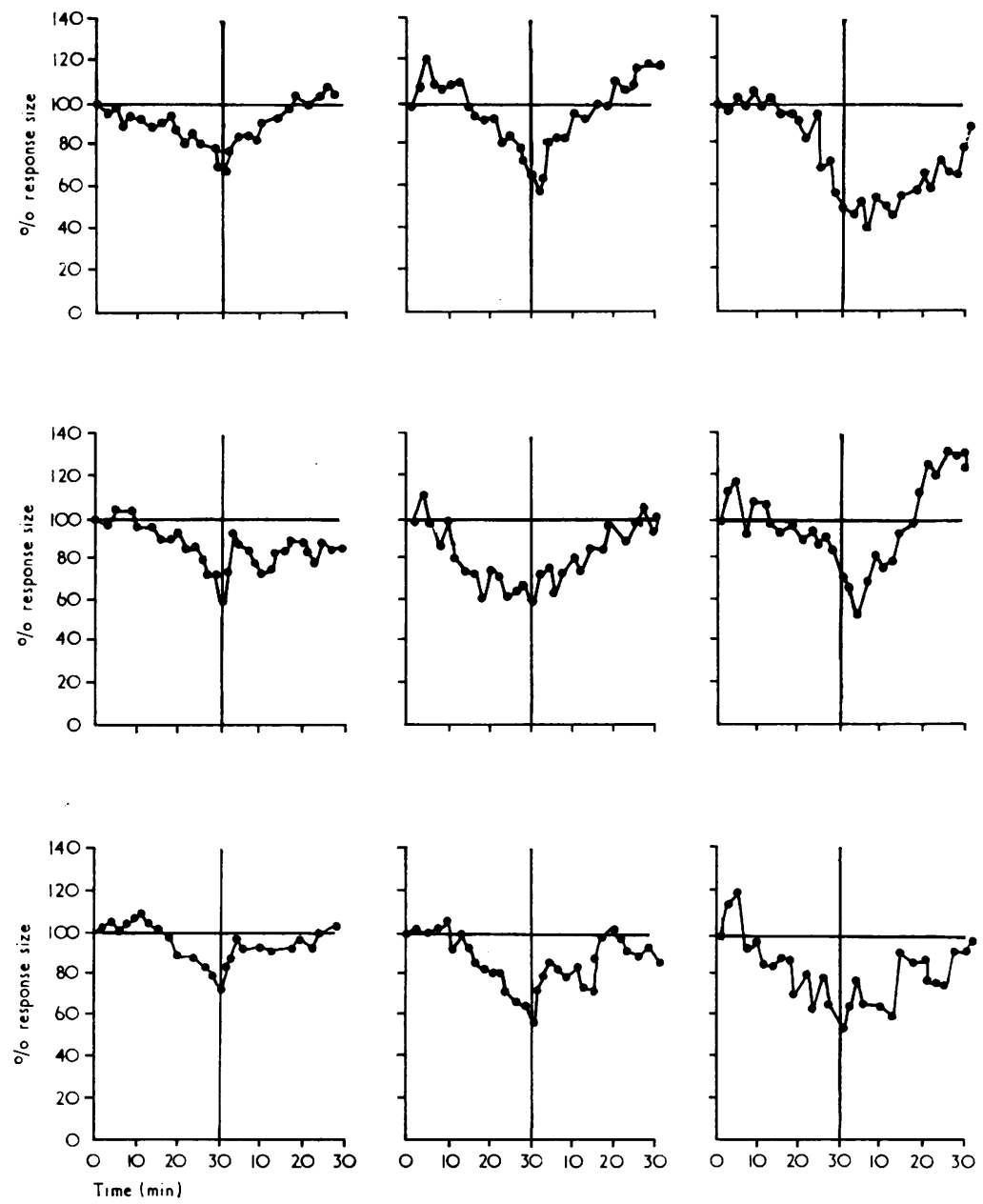

FIG. 4. Results obtained from nine diabetic subjects, showing effects of ischaemia on the response to a sub-maximal stimulus.

latency from $1 \cdot 9-2 \cdot 5 \mathrm{msec}$. These values are well within the normal ranges for subjects of the comparable control group, making it very unlikely that the nerves of these diabetic subjects had suffered a selective loss of function of the fibres of the low threshold group.

Steiness (1959) has demonstrated an increase in the vibration perception threshold in the legs of diabetic subjects. However, when the lower limbs of diabetics were rendered ischaemic with a pneumatic cuff around the thigh, it was found that these subjects were able to perceive the stimulus on the toes for longer periods than non-diabetic subjects and that in some diabetics the threshold remained almost unchanged during the $30-\mathrm{min}$ period of experimental ischaemia. It has been shown (Steiness, 1961a) that it was not possible to increase the time of perception of the stimulus in normal subjects by inducing hyperglycaemia in them, that the abnormal condition in diabetics was reversible, and that it bore some relationship to the state of control of the diabetes (Steiness, 1961b). A similar increase in the vibration perception threshold has been found when the index fingers of diabetics were stimulated, but there was no correlation between this increase of threshold and the duration or state of control of the diabetes (Steiness, 1963).

The behavioural difference of the nerve of the diabetic subject may be due to the fact that the metabolites released from the tissues of the diabetic 


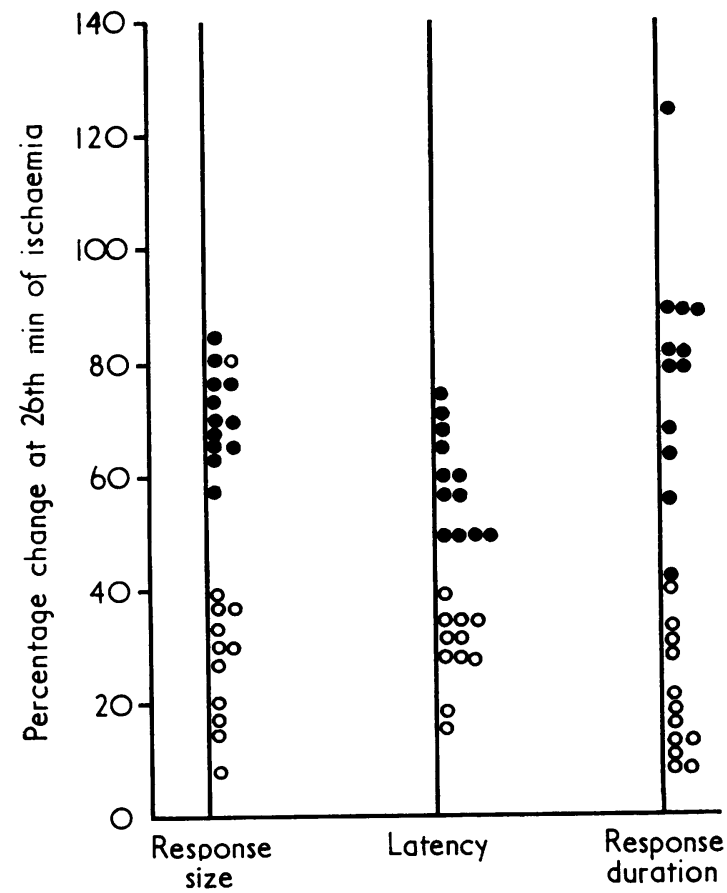

FIG. 5. Percentage changes of response size, latency, and duration at the 26th minute of ischaemia in 12 diabetic subjects $(\bigcirc)$ and 12 control subjects $(\bigcirc)$.

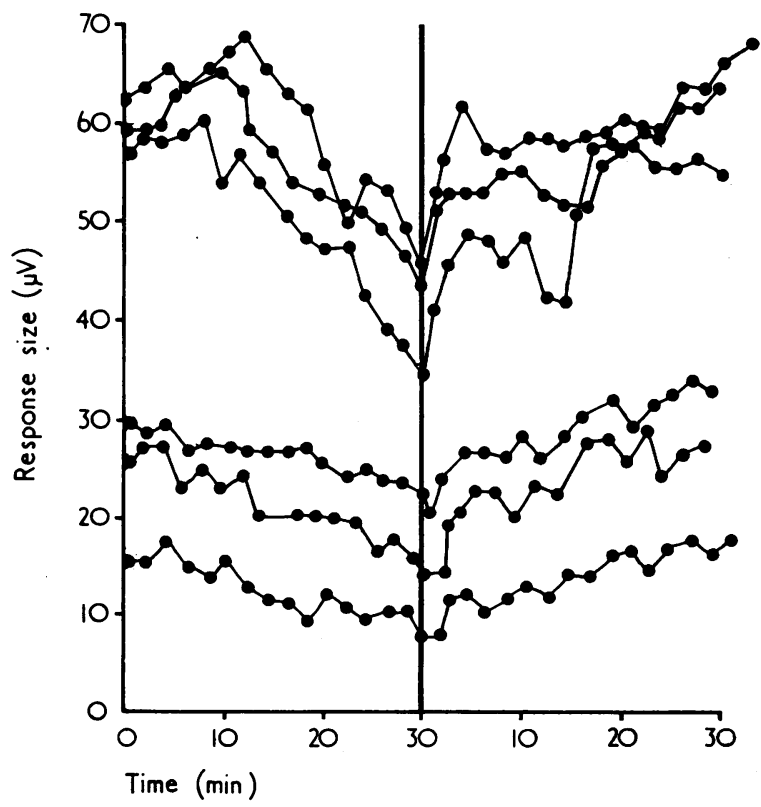

subject during vascular occlusion are essentially different from those produced by the tissues of $\bar{Z}$ normal subjects. Another possibility is that there is no essential difference between the metaboliteso produced by the normal and diabetic subject during a period of vascular occlusion, but that there is $a^{6}$ functional difference in the ability of the diabetic(o) nerve to maintain its activity under ischaemicos conditions.

Maruhashi and Wright (1967) believe that the inactivation of the action potential mechanism of $\Rightarrow$ the nerve by anoxia is due primarily to the failure of its oxidative metabolic processes to maintain? the re-synthesis of the ATP of the membrane enzyme complex. Since the membrane calcium $\frac{\bar{\omega}}{5}$

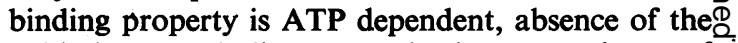
oxidative metabolic energy leads to a release of calcium from the membrane resulting in a reduction of the membrane resistance and potential, leading. eventually to a decline and extinction of the action $\vec{\omega}$ potential. De Sibrik and O'Doherty (1967) believeo that a peripheral nerve seems to have available both the direct oxidative and the glycolytic cycles ando that, under varying conditions, a controlling mechan- $-\omega$ ism probably selects the pathway from which energo is most economically derived. The enhanced sistance of the diabetic nerve to ischaemia may hence be due to its ability to maintain the re-synthesis 5

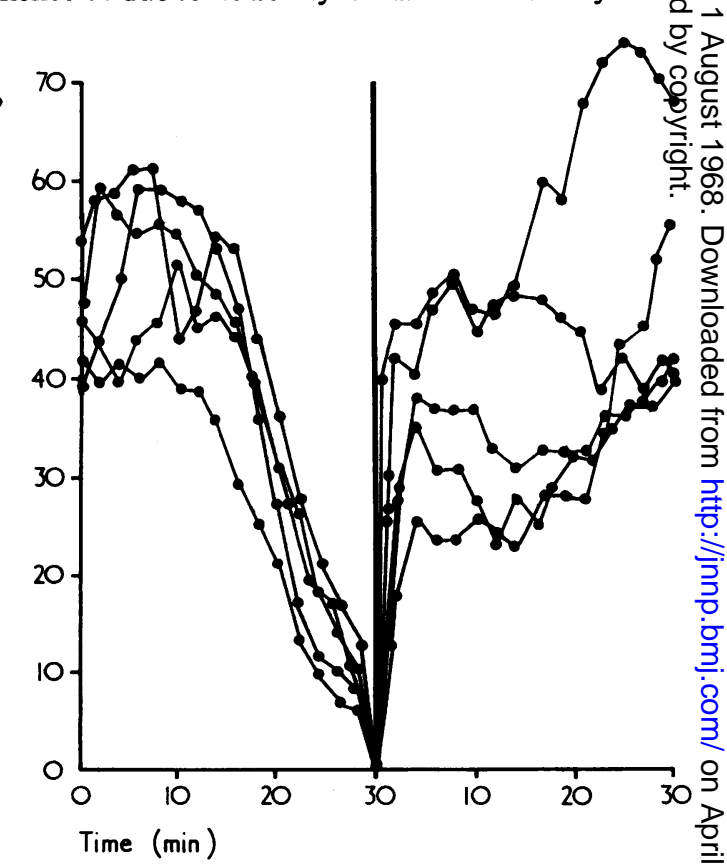

FIG. 6(a) Effect of ischaemia on response size in microvolts in six diabetic subjects; upper three plots from subjects in Group $A$ and lower three from subjects in Group $B$. .

FIG. 6(b) Effect of ischaemia on response in microvolts in five control subjects. 
of ATP under anoxic conditions by utilizing energy derived from a non-oxidative metabolic process. Steiness (1961b) observed that the abnormal resistance of the diabetic nerve to ischaemia was reversible during intense insulin therapy. Heller and Hesse (1960) suggest that the effect of insulin is due to some action on surface membranes of the nerve, permitting further entry of glucose. This view supports the contention that active control of the diabetes may determine whether the nerve utilizes an oxidative or non-oxidative cycle for its energy production and ATP re-synthesis.

Gilliatt (1965) and Thomas and Lascelles (1966) suggest that the basic pathological process in diabetic neuropathy is segmental demyelination and that this could account for many of the clinical features of the condition, as well as for the widespread slowing of the nerve conduction velocity. In our patients of Group A there was no evidence of a motor or sensory nerve conduction defect. However, they all showed a marked abnormality in their response to ischaemia. This would suggest that there are functional changes which occur in the nerve even before structural changes can be demonstrated in the myelin sheath. Thomas and Lascelles (1966) have reviewed the evidence which relates the process of segmental demyelination to a metabolic disturbance of the Schwann cells. Locke (1967) has reviewed the evidence suggesting an intimate metabolic interrelation between the Schwann cell and the axon. The histochemical studies of De Sibrik and O'Doherty (1967) have shown that the activity of glycerophosphate dehydrogenase increases during demyelination. Since this occurs as a result of the release of the enzyme which is normally found in a bound form within the axon, they suggest that this release could provide a mechanism for the regulation of the myelin by the axon. The changes in the functional behaviour of the diabetic nerves that have been reported in this study hence poses the problem of whether the segmental demyelination is a consequence of the prolonged utilization by the axons of an abnormal non-oxidative metabolic cycle.

\section{SUMMARY}

Twelve patients with diabetes mellitus have been studied in this series. Six of them showed no evidence of a peripheral neuropathy as determined by clinical and conventional electro-diagnostic procedures, while six of a comparable age group had evidence of a neuropathy.
All 12 patients showed a common response pattern when their upper limbs were subjected to ischaemia. This pattern, as compared with that of normal subjects, was characterized by a relative constancy of the size, latency, and duration of the evoked sensory nerve potential during a half-hour period of complete vascular occlusion.

We wish to thank Professor K. Rajasuriya, professor of medicine, University of Ceylon, Colombo, for permission to study patients under his care and Professor David Whitteridge, F.R.S., for his advice and criticism of this paper.

\section{REFERENCES}

De Sibrik, I., and O'Doherty, D. (1967). Peripheral nerve glycolysis in Wallerian degeneration. Arch. Neurol. (Chic.). 16, 628-634.

Downie, A. W., and Newell, D. J. (1961). Sensory nerve conduction in patients with diabetes mellitus and controls. Neurology (Minneap.), 11, 876-882.

Gilliatt, R. W., and Willison, R. G. (1962). Peripheral nerve conduction in diabetic neuropathy. J. Neurol. Neurosurg. Psychiat., 25, 11-18.

Gilliatt, R. W. (1965). Clinical aspects of diabetic neuropathy. In Biochemical Aspects of Neurological Disorders, 2nd Series, pp. 117-142. Ed J. N. Cumings and M. Kremer, Blackwell, Oxford.

Heller, I. H., and Hesse, S. (1960). Action of insulin on the respiration of rat sciatic nerve. Lancet, 2, 406-407.

Lawrence, D. G., and Locke, S. (1961). Motor nerve conduction velocity in diabetes. Arch. Neurol. (Chic.), 5, 483-489.

Locke, S. (1967). Axons, Schwann cells and diabetic neuropathy. Bull. N.Y. Acad. Med., 43, 784-791.

Maruhashi, J., and Wright, E. B. (1967). Effect of oxygen lack on the single isolated mammalian (rat) nerve fiber. $J$. Neurophysiol., 30, 434-452.

Mulder, D. W., Lambert, E. H., Bastron, J. A., and Sprague, R. G. (1961). The neuropathies associated with diabetes mellitus, a clinical and electromyographic study of 103 unselected diabetic patients. Neurology (Minneap.), 11, 275-284.

Poole, E. W. (1956a). Ischaemic and post-ischaemic paraesthesiae: Normal response in the upper limb with special reference to the effect of age. J. Neurol. Neurosurg. Psychiat., 19, 148-154.

- (1956b). Ischaemic and post-ischaemic paraesthesiae in polyneuritis. J. Neurol. Neurosurg. Psychiat., 19, 281-288.

Seneviratne, K. N., and Peiris, O. A. (1968). The effect of ischaemia on the excitability of human sensory nerve. J. Neurol. Neurosurg. Psychiat., 31, 338-347.

Skillman, T. G., Johnson, E. W., Hamwi, G. J., and Driskill, H. J. (1961). Motor nerve conduction velocity in diabetes mellitus. Diabetes, 10, 46-51.

Steiness, I. (1959). Vibratory perception in diabetics during arrested blood flow to the limb. Acta med. scand., 163, 195-205.

- (1961a). Vibratory perception in non-diabetic subjects during ischaemia, with special reference to the conditions in hyperglycaemia, after carbohydrate starvation, and after cortisone administration. Acta med. scand., 169, 17-26.

- (1961b). Influence of diabetic status on vibratory perception during ischaemia. Acta med. scand., 170, 319-338.

- (1963). Diabetic neuropathy. Vibration sense and abnormal tendon refiexes in diabetics. Acta med. scand., Suppl. 394, 91.

Thomas, P. K., Sears, T. A., and Gilliatt, R. W. (1959). The range of conduction velocity in normal motor nerve fibres to the small muscles of the hand and foot. J. Neurol. Neurosurg. Psychiat., 22, 175-181.

Thomas, P. K., and Lascelles, R. G. (1966). The pathology of diabetic neuropathy. Quart. J. Med., 35, 489-509.

W.H.O. (1965). Diabetes mellitus. Report of a W.H.O. expert committee. Wld Hlth Org. techn. Rep. Ser., 310, 44. 